\title{
Real-time 10Gbps Polarization Independent Quasicoherent Receiver for NG-PON2 Access Networks
}

\author{
Jose A. Altabas, Guillermo Silva Valdecasa, Lau F. Suhr, Morten Didriksen, Jose A. Lazaro, Member, \\ IEEE, Ignacio Garces, Member, IEEE, Idelfonso Tafur Monroy, Senior Member, IEEE, Anders T. \\ Clausen and Jesper B. Jensen
}

\begin{abstract}
In this paper, we propose and test experimentally a real-time $10 \mathrm{Gbps}$ polarization independent quasicoherent receiver for NG-PON2 access networks. The proposed $10 \mathrm{Gbps}$ quasicoherent receiver exhibits a sensitivity of $-35.2 \mathrm{dBm}$ after $40 \mathrm{~km}$ SSMF transmission with a commercial generic EML as transmitter. This sensitivity means a $14.9 \mathrm{~dB}$ improvement over a direct detection scheme with a photodiode after $40 \mathrm{~km}$ SSMF transmission. Therefore, the use of the proposed $10 \mathrm{Gbps}$ quasicoherent receiver with the tested EML will provide a power budget of $35.64 \mathrm{~dB}$ (class E2) and a splitting ratio of 128 after the $40 \mathrm{~km}$ SSMF transmission. Finally, the proposed $10 \mathrm{Gbps}$ quasicoherent receiver allows a colorless and optical filterless operation because wavelength selection is done by tuning the local oscillator wavelength and using electrical intermediate frequency filtering.
\end{abstract}

Index Terms-NG-PON2, TWDM, Coherent receiver, Access network, PON

\section{INTRODUCTION}

$\mathrm{D}$ URING the recent years, data traffic over optical access networks has grown exponentially. This data traffic growth will continue in the future because of the high bandwidth demand due to the expansion of current services such as streaming media, Internet of Things (IoT) and cloud

This work was supported in part by the Diputación General de Aragón under grant T20_17R, the Spanish MINECO projects FOANT (TEC201785752-R) and ALLIANCE (TEC2017-90034-C2-2-R) co-funded by FEDER, and a MECD FPU grant (FPU-13/00620). This paper was partially presented at the Optical Fiber Communication Conference and Exposition, San Diego Convention Center, San Diego, CA, USA, March 2018. (Corresponding author: J. A. Altabas.)

J. A. Altabas and I. Garces are with the Department of Electrical Engineering and Communications, Aragon Institute of Engineering Research, University of Zaragoza, Zaragoza 50018, Spain (e-mail: jaltabas@unizar.es; ngarces@unizar.es).

G. Silva Valdecasa, L. F. Suhr, M. Didriksen and J. B. Jensen are with the Bifrost Communications, Scion DTU, Akademivej Bygnig 381, 2800 Kgs Lyngby, Denmark.

J. A. Lazaro is with the School of Telecommunications Engineering, Polytechnic University of Catalonia, Barcelona 08034, Spain (e-mail: jose.lazaro@tsc.upc.edu).

I. Tafur Monroy is with the Institute for Photonics Integration, Eindhoven University of Technology, Eindhoven 5600 MB, The Netherlands (e-mail: i.tafur.monroy@tue.nl).

A. T. Clausen is with DTU Fotonik, Technical University of Denmark (DTU), Ørsteds Plads, 2800 Kgs. Lyngby, Denmark (e-mail: ancl@fotonik.dtu.dk). computing; the development of new services using virtual and augmented reality technologies [1] and the convergence of wireless and optical access networks on the 5G paradigm [2].

In order to address the current and future data traffic requirements, the NG-PON2 standard for passive optical networks (PON) was recently released [3, 4]. The NG-PON2 standard is based on time and wavelength division multiplexing (TWDM) through four wavelength channels at a data rate of $10 \mathrm{Gbps}$ per channel and providing an aggregated data rate of 40 Gbps.

The NG-PON2 standard has high demanding requirements for both network and devices in order to satisfy this growing user data traffic and the operators' necessities. The TWDM operation of NG-PON2 requires 10 Gbps colorless and tunable optical network units (ONU), as can be seen in Fig. 1. In addition, the NG-PON2 standard proposes optical distribution networks (ODN) with high splitting ratios, up to 256, and long transmission distances, up to $40 \mathrm{~km}$. These high demanding technical requirements increase the cost of the ONU because of the necessity of using optical tunable filters, high sensitivity avalanche photodiodes (APD) [5, 6], optical amplifiers and high optical power and wavelength stable transmitting lasers.

Coherent technologies [7] have been researched during the recent years as a promising solution to satisfy these more and more demanding requirements of the optical access network. Cost-effective emitters have been proposed for coherent optical access networks as directly-phase modulated

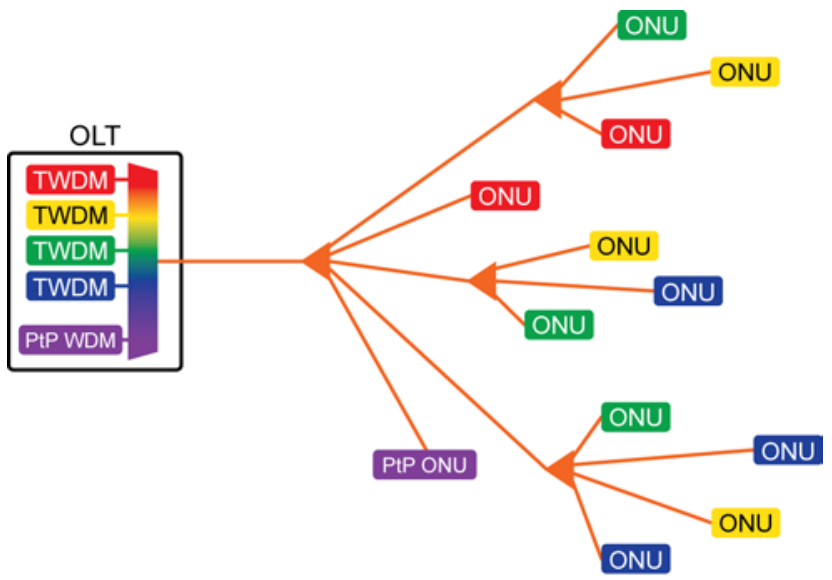

Fig. 1. NG-PON2 network. 


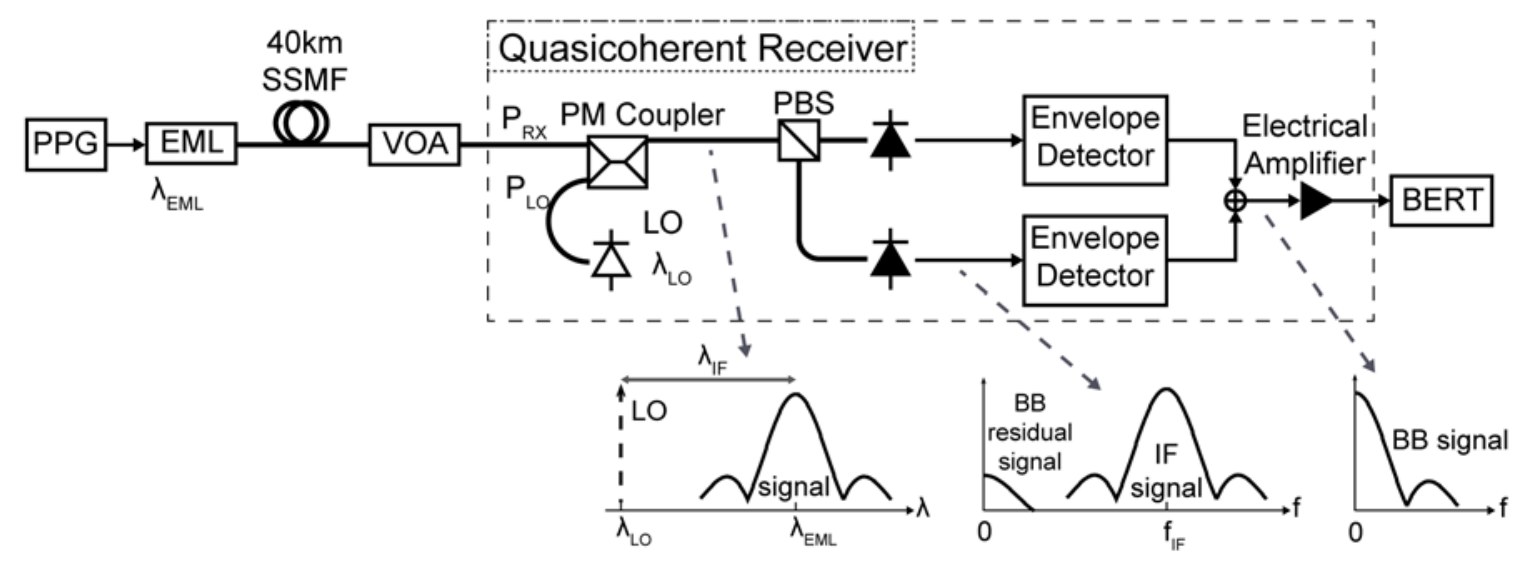

Fig. 2. Experimental setup. Insets: LO and signal spectrum schematic, heterodyne downconverted signal and baseband received signal.

distributed feedback lasers (DFB) [8, 9], directly-phase modulated reflective semiconductor amplifiers (RSOA) [10, 11], intensity modulated vertical cavity surface emitting lasers (VCSEL) [12] or directly-phase modulated VCSELs [13]. In addition, several coherent receiver technologies have also been proposed and developed. These proposals have a special focus on polarization independence or polarization control as it is an issue for low cost coherent receivers. One of the first proposals was made by Glance [14] using a similar setup but designed for digital DPSK signals, when our proposal is managing analog signals. This same architecture has been proposed in other works for coherent optical access [15]. Other solutions based on different designs use 3x3 couplers [16], polarization scrambling at the transmitter [17] or Alamouti encoding at the transmitter side [18]. Additionally, coherent receivers for optical access networks demand as reduced as possible digital signal processing (DSP) [19], [20] after the optical reception in order to keep the ONU complexity as simple as possible.

This work proposes a real-time $10 \mathrm{Gbps}$ polarization independent quasicoherent receiver for NG-PON2 access networks, extending and completing our previously published results presented in [21]. In particular, we will add to the previous results: the spectral characteristics of the source, the intermediate frequency shift for the receiver given the characteristics of the emitter, a comparison of the behaviour between the direct detection (DD) scheme and the quasicoherent receiver for back to back and $40 \mathrm{~km}$ links, and a discussion of the available power budget, addressing the performance of the receiver in terms of splitting ratio and the NG-PON2 class than can be fulfilled with it. We will see that the receiver allows an increase of its sensitivity in order to fulfil the NG-PON2 requirements without using APDs at the receiver or high power lasers at the transmitter and therefore achieving a cost effective receiver architecture adequate for the ONUs and the optical line terminals (OLTs) of a passive optical access network. In addition, the real-time $10 \mathrm{Gbps}$ polarization independent quasicoherent receiver enables a colorless operation without expensive tunable optical filters and a real-time operation without additional DSP keeping a low complexity of the receiver.

\section{EXPERIMENTAL SETUP}

The schematic of the real-time polarization independent 10 Gbps quasicoherent receiver is shown in Fig. 2 and denoted as Quasicoherent Receiver. Fig. 2 also shows the experimental setup employed to test the quasicoherent receiver.

The first part of the $10 \mathrm{Gbps}$ receiver consists of a polarization maintaining (PM) optical coupler, which is used to combine the receiver signal and the local oscillator (LO). The LO is connected to the PM coupler in such a way that at the output the power is splitted at $50 \%$ in both principal polarization axes. The $\mathrm{LO}$ consists of an external cavity laser (ECL) with $100 \mathrm{kHz}$ linewidth and $-145 \mathrm{~dB} / \mathrm{Hz}$ Relative Intensity Noise (RIN). The ECL was selected as LO because it eases the tuning of the emitting wavelength and its output optical power. We have also tested several Distributed Feedback (DFB) lasers as LO presenting linewidths up to $~ 10$ $\mathrm{MHz}$ and we have found that the sensitivity results are basically the same. These DFB lasers had also RIN values in the range of, or lower than $-145 \mathrm{~dB} / \mathrm{Hz}$ so the noise characteristics of the DFBs are similar to these of the ECL.

After the optical coupler, the signal and LO go through a polarization beam splitter (PBS) and are received using two high bandwidth photodiodes (PD). The LO wavelength $\left(\lambda_{\mathrm{LO}}\right)$ is shifted away a value of $\lambda_{\mathrm{IF}}$ from the signal wavelength $\left(\lambda_{\mathrm{EML}}\right)$ in order to downconvert the received signal to an intermediate frequency (IF) when the signal and LO are received with the PDs, as is depicted in the inset of Fig. 2. Two types of PDs have been employed in this article. The first analysis of the quasicoherent receiver has been made using two standard commercial PDs presenting an electrical bandwidth of $23 \mathrm{GHz}$, as the result presented on [21]. The sensitivity and the intermediate frequency shift measurements have been made employing two slightly better sensitivity commercial PDs with $33 \mathrm{GHz}$ electrical bandwidth, but maintaining the same IF and measurement conditions. These new PDs will permit in the future to obtain higher intermediate frequencies thus allowing future increases in the available user bandwidth.

The received intermediate frequency signal is then downconverted to baseband, as is shown in Fig. 2, employing 


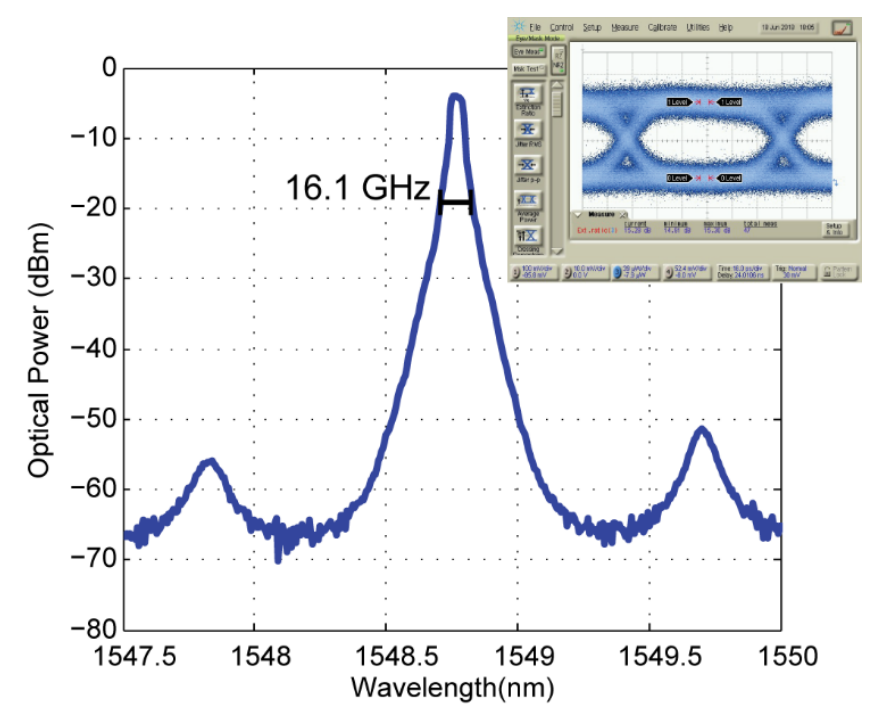

Fig. 3. Optical Spectrum of TX signal. Inset: Eye diagram of TX signal.

two 10 Gbps ultra-wideband envelope detectors (ED) [21], similar to the ones presented on [22] but designed to support 10 Gbps signals. After the downconversion of the signals to baseband, both signals are electrically added and then amplified. Finally, the Bit Error Rate (BER) is measured using a real-time BER test (BERT). Therefore, the $10 \mathrm{Gbps}$ polarization independent quasicoherent receiver does not require any kind of digital signal processing (DSP) after the reception to measure its performance as is generally needed in heterodyne coherent receivers, allowing a simple real-time operation for a quasicoherent scheme.

The designed testbed consists of a $10 \mathrm{Gbps}$ transmitter, $40 \mathrm{~km}$ of Standard Single Mode Fiber (SSMF) and a variable optical attenuator (VOA). The transmitter used to test the described real-time $10 \mathrm{Gbps}$ polarization independent quasicoherent receiver is a commercial, $80 \mathrm{~km}-10 \mathrm{Gbps}$ bandwidth external modulated laser (EML) emitting $0.44 \mathrm{dBm}$ optical power. The transmitter is modulated with a $10 \mathrm{Gbps}$ non-return to zero (NRZ) data signal coming from a pulse pattern generator (PPG). The optical spectrum of the transmitted signal is shown Fig. 3 . We can see that the $\lambda_{\text {EML }}$ is $1548.75 \mathrm{~nm}$ and the bandwidth at $-15 \mathrm{~dB}\left(\mathrm{BW}_{-15 \mathrm{~dB}}\right)$ is 16.1 GHz. The inset of Fig. 3 shows the eye diagram of the transmitted signal and from it the extinction ratio is estimated to be $15.28 \mathrm{~dB}$.

Fig. 4 shows how the evolution of BER curves as a function of the received power $\left(\mathrm{P}_{\mathrm{RX}}\right)$ for different $\mathrm{LO}$ optical powers $\left(\mathrm{P}_{\mathrm{LO}}\right)$, similar to the measurements made in [1]. $\mathrm{P}_{\mathrm{LO}}$ is varied from $6.5 \mathrm{dBm}$ to $14.5 \mathrm{dBm}$ in steps of $2 \mathrm{~dB}$. The $P_{\mathrm{LO}}$ increment causes a reduction of the required $P_{R X}$ to obtain a given BER value i.e. an improvement of the sensitivity of the 10 Gbps quasicoherent receiver. As the curves depicted in Fig. 4 are nearly parallel straight lines, the $\mathrm{P}_{\mathrm{RX}}$ reduction is the same almost for any measured BER. For the first $2 \mathrm{~dB}$ of $\mathrm{P}_{\mathrm{LO}}$ increase, the improvement of the sensitivity is around $1.25 \mathrm{~dB}$. This improvement gets saturated after increasing the $\mathrm{P}_{\mathrm{LO}}$ over $10.5 \mathrm{dBm}$ and the required $\mathrm{P}_{\mathrm{RX}}$ reduction falls approximately to $0.75 \mathrm{~dB}$ for the last $2 \mathrm{~dB}$ of $\mathrm{P}_{\mathrm{LO}}$ increment. This behavior is compatible with a receiver limited by shot noise, which is

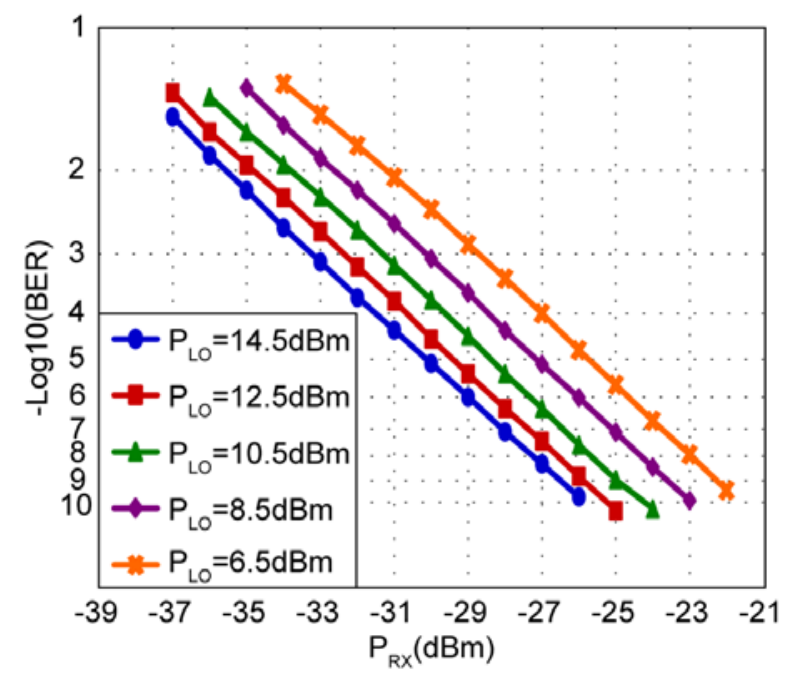

Fig. 4. BER versus received power for 10Gbps quasicoherent receiver for different LO power.

going to be higher than the LO-RIN that will have a greater contribution to the overall noise as our receiver is not balanced. As a consequence of this characterization, the increment of $8 \mathrm{~dB}$ of the $\mathrm{P}_{\mathrm{LO}}$ causes an accumulated $\mathrm{P}_{\mathrm{RX}}$ reduction of $4 \mathrm{~dB}$ and therefore a $\mathrm{P}_{\mathrm{LO}}$ of $14.5 \mathrm{dBm}$ will be used because it provides the best BER value for any received optical power.

\section{RESUlts AND Discussion}

In this section, the performance of the $10 \mathrm{Gbps}$ quasicoherent receiver is tested and discussed. The performance analysis is based on the receiver sensitivity, the maximum IF shift allowed by the quasicoherent receiver and its relation with the maximum spectral excursion (MSE) of the transmitters, and the achievable power budget.

The receiver sensitivity has been defined as the minimum received power with a maximum BER of $10^{-3}$, which is the maximum allowed BER by the forward error correction (FEC) as stated on the NG-PON2 standard [4]. Fig. 5 shows the receiver sensitivity curves for the proposed quasicoherent receiver and a direct detection scheme (DD) for back-to-back (BTB) and for $40 \mathrm{~km}$ SSMF transmission. The DD reception is performed using a PD with the same features than these used in the quasicoherent receiver and the same electrical amplifier in order to have a useful comparison.

The receiver sensitivity exhibited by the $10 \mathrm{Gbps}$ quasicoherent receiver is $-35.2 \mathrm{dBm}$ for BTB transmission. The quasicoherent receiver exhibits a null dispersion penalty after $40 \mathrm{~km}$ SSMF transmission, as it can be seen from figure 5, due to the use of an EML in combination with the filtering characteristics of the envelope detector. The BTB receiver sensitivity with DD is $-20.9 \mathrm{dBm}$ and exhibits a dispersion penalty of $0.6 \mathrm{~dB}$ after $40 \mathrm{~km}$ SSMF transmission. Therefore, the proposed $10 \mathrm{Gbps}$ real-time polarization independent quasicoherent receiver has a $14.3 \mathrm{~dB}$ sensitivity improvement in comparison with a DD scheme. This improvement increases to $14.9 \mathrm{~dB}$ when the dispersion penalty of $40 \mathrm{~km}$ SSMF transmission is included. Typical avalanche photodiodes 


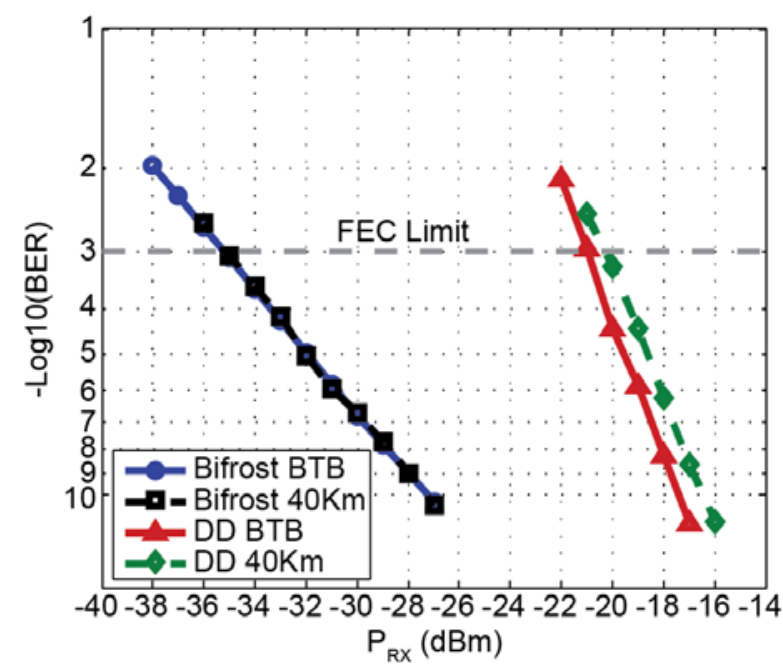

Fig. 5. BER vs. received power for 10Gbps quasicoherent receiver and DD.

(APD) only provide an improvement between 5 and $10 \mathrm{~dB}$ in comparison with the PDs [6, 7].

The maximum IF shift is defined as the maximum IF range that provides at least a target receiver sensitivity. This IF range varies due to the electrical bandwidth of the PDs, which in these measurements was of $33 \mathrm{GHz}$. Fig. 6 shows the receiver sensitivity of the 10 Gbps quasicoherent receiver for each IF generated after the PDs. The sweep of the IF has been done varying the LO wavelength and keeping the transmitter (TX) wavelength fixed for simplicity. These results would be the same if the TX wavelength was varied and the $\mathrm{LO}$ wavelength was kept fixed. The maximum IF shift for a receiver sensitivity of $-34 \mathrm{dBm}$ is $17.2 \mathrm{GHz}$. This maximum IF shift can be increased to $20 \mathrm{GHz}$ with $1 \mathrm{~dB}$ of penalty and to 23.4GHz with $2 \mathrm{~dB}$ of penalty as can be seen in Fig. 6 .

The maximum spectral excursion (MSE) of a transmitter is defined as "the absolute difference between the nominal central frequency of the wavelength channel and the $-15 \mathrm{~dB}$ point of the transmitted spectrum furthest from the nominal central frequency" [5]. Although the MSE is a parameter related to the transmitter, it is relevant for the $10 \mathrm{Gbps}$ quasicoherent receiver because it may determine its colorless and optical filterless operation, which are desired characteristics for a NGPON2 receiver. In a PON architecture, the nominal central frequency or wavelength of the transmitter may change due to many different causes, being a burst transmitter one of them, and the bit rate and chirp characteristics of the transmitter will determine its $\mathrm{BW}_{-15 \mathrm{~dB}}$. The $10 \mathrm{Gbps}$ quasicoherent receiver allows a colorless operation by using the $\mathrm{LO}$ as the selector of the receiver wavelength channel, provided that the signal spectrum does not vary too much. The optical filterless operation of the 10Gbps quasicoherent receiver is achieved because the LO downconverts the selected channel to IF and then the signal is electrically filtered, but an increase of the transmitter signal spectrum may cause an additional excursion of the IF. So, the proposed receiver design may avoid expensive optical tunable filters on the receiver to obtain a colorless operation, but clearly the maximum IF shift of the quasicoherent receiver is

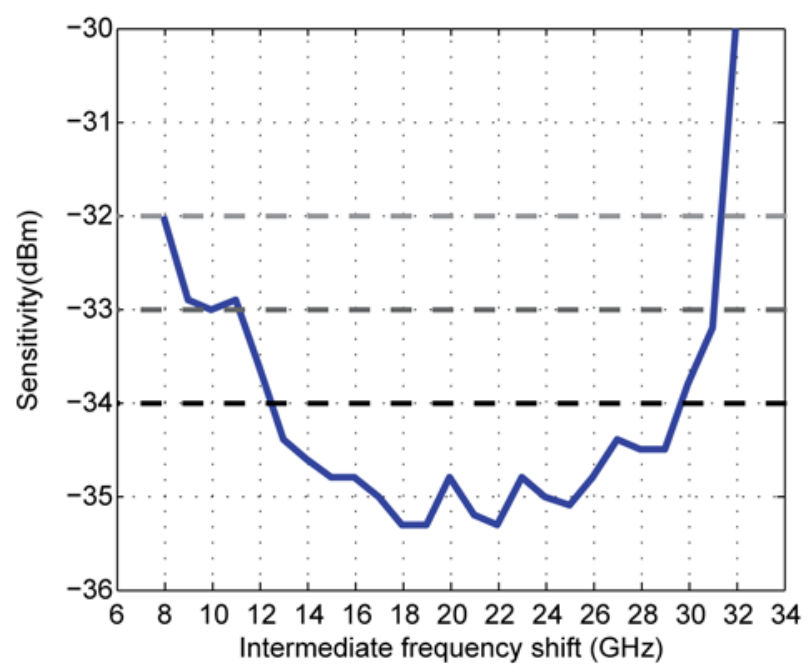

Fig. 6. Intermediate frequency shift for 10Gbps quasicoherent receiver.

relevant in relation with the MSE of the transmitter.

The MSE sets a limit on the transmitter wavelength fluctuation because its value is the combination of its wavelength variation and the $\mathrm{BW}_{-15 \mathrm{~dB}}$ of the transmitted signal. Therefore, the MSE value sets the maximum IF fluctuation allowed for the $10 \mathrm{Gbps}$ quasicoherent receiver to operate as a colorless one. The NG-PON2 standard defines a MSE of $\pm 12.5 \mathrm{GHz}$ for $50 \mathrm{GHz}$ channel spacing and a MSE of $\pm 20 \mathrm{GHz}$ for $100 \mathrm{GHz}$ channel spacing. Therefore, the maximum IF shift is dependent on the sensitivity of the receiver but also on the variation of the spectrum of the transmitted signal, as it is important that the complete spectrum of the signal fits within the limits of the maximum IF shift of the receiver.

The MSE values defined within the NG-PON2 standard and the 10Gbps quasicoherent receiver measured MSE compatibilities are summarized on Table I. The $10 \mathrm{Gbps}$ quasicoherent receiver will provide a receiver sensitivity of -34 dBm being compatible with transmitters that have an MSE of $\pm 16.65 \mathrm{GHz}$. Therefore, the $10 \mathrm{Gbps}$ quasicoherent receiver can operate with transmitters designed for $50 \mathrm{GHz}$ channel spacing network on the NG-PON2 standard. If the required receiver sensitivity can drop to $-32 \mathrm{dBm}$, the $10 \mathrm{Gbps}$ quasicoherent receiver will be compatible with transmitters with a MSE of $\pm 19.75 \mathrm{GHz}$. This MSE value is close enough to the MSE requirement of the transmitters that operate with $100 \mathrm{GHz}$ channel spacing of the NG-PON2 standard and so compatible with them.

An important parameter for NG-PON2 networks is the power budget of the link because it will determine the maximum reach and splitting ratio of the deployed network

TABLE I

MSE VALUES FOR UPSTREAM TRANSMITTERS AND QUASICOHERENT RECEIVER COMPATIBILITY

\begin{tabular}{lcc}
\hline \hline \multicolumn{1}{c}{ Channel Spacing } & $50 \mathrm{GHz}$ & $100 \mathrm{GHZ}$ \\
\hline NG-PON2 requirement & $\pm 12.5 \mathrm{GHz}$ & $\pm 20 \mathrm{GHz}$ \\
Quasicoherent receiver with $\mathrm{P}_{\mathrm{RX}}$ of $-34 \mathrm{dBm}$ & $\pm 16.65 \mathrm{GHz}$ & - \\
Quasicoherent receiver with $\mathrm{P}_{\mathrm{RX}}$ of $-32 \mathrm{dBm}$ & $\pm 19.75 \mathrm{GHz}$ & $\pm 19.75 \mathrm{GHz}$ \\
\hline \hline
\end{tabular}


TABLE II

POWER BUDGET, SPLITTING RATIO AND NG-PON2 CLASS SUMMARY

\begin{tabular}{lcccccc}
\hline \hline & & Testing EML & & \multicolumn{3}{c}{ Standard NG-PON2 TX } \\
& Power budget & Splitting ratio & NG-PON2 class & Power budget & Splitting ratio & NG-PON2 class \\
\hline $\begin{array}{l}\text { Quasicoherent receiver with the } \\
\text { best sensitivity value }\end{array}$ & $35.64 \mathrm{~dB}$ & 128 & $\mathrm{E} 2$ & $37.2 \mathrm{~dB}$ & 128 & E2 \\
$\begin{array}{l}\text { Quasicoherent receiver compatible } \\
\text { with 50 GHz channel spacing }\end{array}$ & $34.44 \mathrm{~dB}$ & 64 & $\mathrm{E} 1$ & $36 \mathrm{~dB}$ & 128 & E2 \\
$\begin{array}{l}\text { Quasicoherent receiver compatible } \\
\text { with 100 GHz channel spacing }\end{array}$ & $32.44 \mathrm{~dB}$ & 64 & $\mathrm{~N} 2$ & $34 \mathrm{~dB}$ & 64 & E1 \\
$\begin{array}{l}\text { DD - PIN (as measured in this } \\
\text { work) }\end{array}$ & $21.34 \mathrm{~dB}$ & 8 & - & $22.3 \mathrm{~dB}$ & 16 & - \\
DD - APD [23] & $30.94 \mathrm{~dB}$ & 32 & $\mathrm{~N} 1$ & $32.5 \mathrm{~dB}$ & 64 & $\mathrm{~N} 2$ \\
\hline \hline
\end{tabular}

and so the profit that its exploitation will provide to the operator. In this case, we will define the power budget as the difference between the transmitted power and the receiver sensitivity after $40 \mathrm{~km}$ SSMF transmission. The dispersion penalty has been subtracted from the power budget in order to show just the allowed optical path losses. In the power budget calculation, the fiber attenuation is considered as $0.25 \mathrm{~dB} / \mathrm{km}$ and the splitter losses are considered as $3.5 \log 2(\mathrm{M}) \mathrm{dB}$ with $\mathrm{M}$ being the splitting ratio [4].

We will discuss the obtainable power budget using the tested EML as the transmitter but also using typical NG-PON2 transmitters, which provide higher optical powers. These other transmitters have not been measured in this work, but their emitted optical power nominal values, as shown in the standard, have been used as a comparison.

The proposed 10 Gbps quasicoherent receiver and the EML employed for the setup are able to provide an optical power budget of $35.64 \mathrm{~dB}$ for a $-35.2 \mathrm{dBm}$ receiver sensitivity. This power budget allows to fulfill the requirements of E2 class of the standard. We will compare these values with the optically unfiltered PIN measured in figure 5 (DD-PIN), and also, for a more realistic comparison, with an APD-based optically filtered receiver [23], which presents a sensitivity of about $-30.5 \mathrm{dBm}$. For the first case, if a DD-PIN scheme is used, the power budget drops to $21.44 \mathrm{~dB}$ and in this case it is not able to fulfill the required optical path losses (OPL) of any NGPON2 class. If we consider the DD-APD receiver, the available power budget of $30.94 \mathrm{~dB}$ would fulfill the maximum OPL of NG-PON2 N1 class, which is $29 \mathrm{~dB}$. In terms of splitting ratios, the proposed $10 \mathrm{Gbps}$ quasicoherent receiver would allow a splitting ratio after $40 \mathrm{~km}$ SSMF transmission of 128, whereas the DD-PIN PIN would only allow a splitting ratio after $40 \mathrm{~km}$ SSMF transmission of 8 , which would increase to 32 in the case of using the APDbased receiver.

The EML that we have used on the tests does not fulfill the emitting power requirements of the standard, which has a lower limit of $+2 \mathrm{dBm}$. If a standardized NG-PON2 transmitter is employed, the minimum emitted optical power is $+2 \mathrm{dBm}$. In this case, and considering only emitted optical power variations, the power budget provided by the proposed 10 Gbps coherent receiver would be of $37.2 \mathrm{~dB}$ after $40 \mathrm{~km}$ SSMF transmission. The combination of a standardized NG-PON2 transmitter with the proposed $10 \mathrm{Gbps}$ quasicoherent receiver would fulfil the E2 class of the NG-PON2 standard and would allow a splitting ratio after $40 \mathrm{~km}$ SSMF transmission of 128 , only $0.8 \mathrm{~dB}$ below the optical power necessary to obtain the logical NG-PON2 limit of 256 users. If this standardized NG-PON2 transmitter is received using DD-PIN, the optical power budget falls to 22.3 $\mathrm{dB}$, which does not fulfil any NG-PON2 class and will only allow a splitting ratio after $40 \mathrm{~km}$ SSMF transmission of 16 . If the DD-APD receiver is used, the N2 class can be fulfilled and the splitting ratio after $40 \mathrm{~km}$ SSMF transmission will increase to 64 .

Therefore, the proposed $10 \mathrm{Gbps}$ quasicoherent receiver improves the power budget in comparison with the tested DD scheme using a PIN and even with the one that can be expected using an APD-based receiver. This improvement is translated on the fulfillment of a higher NG-PON2 class and a larger splitting ratio after $40 \mathrm{~km}$ SSMF transmission.

These power budget values of the $10 \mathrm{Gbps}$ quasicoherent receiver and the direct detection scheme for the testing EML and for a $+2 \mathrm{dBm}$ optical power standard NG-PON2 transmitter are summarized on Table II, showing the allowed splitting ratios and the NG-PON2 OPL class compatibility.

In a multiwavelength scenario, as is required for the NG-PON2 standard, the transmitted wavelengths can fluctuate in the range defined by the MSE as was stated previously. In addition, the maximum transmitted wavelength variation is related with the sensitivity of the proposed $10 \mathrm{Gbps}$ quasicoherent receiver as we have analyzed before. Thus, the power budget in a multiwavelength scenario will also be related with the MSE and so with the channel spacing.

A channel spacing of $100 \mathrm{GHz}$ imposes a sensitivity of $-32 \mathrm{dBm}$ because of the MSE requirements, as has been explained previously. So, the power budget with a channel spacing of $100 \mathrm{GHz}$ will be of $32.44 \mathrm{~dB}$ with the testing EML and around $34 \mathrm{~dB}$ with a standardized NG-PON2 transmitter. These power budgets allow to fulfill the N2 and E1 classes, respectively, and they will allow splitting ratios of 64 .

If the used channel spacing is $50 \mathrm{GHz}$, the sensitivity improves to $-34 \mathrm{dBm}$ and so the power budgets will be better. The power budget will be of $34.44 \mathrm{~dB}$ when the transmitter is the testing EML and around $36 \mathrm{~dB}$ if a $+2 \mathrm{dBm}$ standardized NG-PON2 transmitter is used. Thus, the E1 and E2 classes are fulfilled with these respective power budgets allowing splitting ratios of 64 and 128 respectively. 


\section{CONCLUSION}

A real-time $10 \mathrm{Gbps}$ polarization independent quasicoherent receiver for NG-PON2 access networks has been presented in this paper. This real-time quasicoherent reception technique is a promising technology for NG-PON2 access networks that allows to solve the most demanding requirements of the NG-PON2 standard.

The proposed $10 \mathrm{Gbps}$ quasicoherent receiver shows a sensitivity of $-35.2 \mathrm{dBm}$ after $40 \mathrm{~km}$ SSMF transmission. This sensitivity provides an improvement of $14.3 \mathrm{~dB}$ in comparison with DD with a PD after the same $40 \mathrm{~km}$ SSMF transmission. In addition, it will be better even with the $5-10 \mathrm{~dB}$ of improvement that an APD would provide.

The 10 Gbps quasicoherent receiver sensitivity will allow a power budget of $35.64 \mathrm{~dB}$ when the testing EML is used or $37.2 \mathrm{~dB}$ when a standardized NG-PON2 transmitter would be used. These power budgets will allow to fulfill the E2 OPL class of the NG-PON2 standard, respectively, whereas direct detection with a PD will not fulfil any OPL classes of NG-PON standard. In addition, the power budgets of the 10 Gbps quasicoherent receiver will give rise to a splitting ratio of 128 in comparison with the 8 and 16, respectively, that will allow direct detection with a PD. Even if an APD is employed for direct detection, the $10 \mathrm{Gbps}$ quasicoherent receiver will increase the splitting ratio at least by a factor 2 .

In addition, the proposed $10 \mathrm{Gbps}$ quasicoherent receiver allows a colorless and optical filterless operation, which is compatible with NG-PON2 transmitters. The colorless operation is possible due to the channel selection done using the tunability of LO and the electrical IF filtering. If the transmitter has a MSE compatible with $50 \mathrm{GHz}$ channel spacing, the quasicoherent receiver will provide a sensitivity of $-34 \mathrm{dBm}$. Whereas the provided sensitivity will be $-32 \mathrm{dBm}$ if the transmitter has a MSE compatible with a $100 \mathrm{GHz}$ channel spacing.

In conclusion, the proposed real-time $10 \mathrm{Gbps}$ polarization independent quasicoherent receiver is a promising receiver for NG-PON2 access networks increasing the available power budgets and allowing colorless and filterless operation compatible with NG-PON2 transmitters.

\section{REFERENCES}

[1] Cisco Visual Networking Index: Global Mobile Data Traffic Forecast Update, 2016-2021, White Paper.

[2] M. Ruffini, "Multidimensional Convergence in Future 5G Networks," J. Lightwave Technol., vol. 35, no. 3, pp. 535-549, Feb. 2017.

[3] J.S. Wey, et al., "Physical Layer Aspects of NG-PON2 Standards-Part 1: Optical Link Design [Invited]," J. Opt. Commun. Netw., vol. 8, no. 1, pp. 33-42, Jan. 2016.

[4] Y. Luo, et al., "Physical layer aspects of NG-PON2 standards-Part 2: System design and technology feasibility [Invited]," J. Opt. Commun. Netw., vol. 8, no. 1, pp. 43-52, Jan. 2016.

[5] J.C. Campbell, "Recent Advances in Telecommunications Avalanche Photodiodes," J. Lightwave Technol., vol. 25, no. 1, pp. 109-121, Jan. 2007.

[6] M. Achouche, et al., "InGaAs Communication Photodiodes: From Lowto High-Power-Level Designs," IEEE Photonics J., vol. 2, no. 3, pp. 460468, Feb. 2010.

[7] M. S. Erkilinç, et al., "Bidirectional wavelength-division multiplexing transmission over installed fibre using a simplified optical coherent access transceiver," Nature communications, vol. 8, Oct. 2017.
[8] J. A. Altabas, et al., "1Gbps full-duplex links for ultra-dense-WDM $6.25 \mathrm{GHz}$ frequency slots in optical metro-access networks," Opt. Express, vol. 24, no. 1, pp. 555-565, Jan. 2016.

[9] I. N. Cano, A. Lerín and J. Prat, "DQPSK Directly Phase Modulated DFB for Flexible Coherent UDWDM-PONs," IEEE Photonics Technol. Lett., vol. 28, no. 1, pp. 35-38, Jan. 2016.

[10] J. A. Altabas, et al., "Cost-Effective Transceiver Based on an RSOA and a VCSEL for Flexible uDWDM Networks," IEEE Photonics Technol. Lett., vol. 28, no. 10, pp. 1111-1114, May 2016.

[11] H. K. Shim, et al., "A practical 10-Gb/s ultra-dense WDM PON," in Proc. OECC/ACOFT, Melbourne, VIC, Australia, Jul. 2014, pp. 289290.

[12] J. B. Jensen, et al., "VCSEL Based Coherent PONs," J. Lightwave Technol., vol. 32, no. 8, pp. 1423-1433, Apr. 2014.

[13] J. A. Altabas, et al., "Chirp-based direct phase modulation of VCSELs for cost-effective transceivers," Opt. Lett., vol. 42, no. 3, pp. 583-586, Feb. 2017.

[14] B. Glance, "Polarization Independent Coherent Optical Receiver," J. Lightwave Technol., vol. LT-5, no.2,1987.

[15] I.N. Cano, et al., "Simplified Polarization Diversity Heterodyne Receiver for 1.25Gb/s Cost-Effective udWDM-PON," Proc. OFC, paper W4G.2, 2014

[16] E. Ciaramella, "Polarization-Independent Receivers for Low-Cost Coherent OOK Systems," IEEE Photonics Technol. Lett., vol. 26, no. 6, pp. 548-551, Mar. 2014.

[17] I. N. Cano, et al., "Polarization independent single-PD coherent ONU receiver with centralized scrambling in udWDM-PONs," in Proc. ECOC, Cannes, France, Sept. 2014, pp. 1-3.

[18] M. S. Faruk, et al., "Technology Requirements for an Alamouti-Coded $100 \mathrm{~Gb} / \mathrm{s}$ Digital Coherent Receiver Using $3 \times 3$ Couplers for Passive Optical Networks," IEEE Photonics J., vol. 10, no. 1, pp. 1-13, Feb. 2018.

[19] L. Xue, et al, "50-Gb/s TDM-PON Based on 10G-Class Devices by Optics-simplified DSP," in Proc. OFC, San Diego, CA, USA, Mar. 2018, pp.1-3.

[20] R. Ferreira, et al., "Demonstration of Nyquist UDWDM-PON with digital signal processing in real-time." in Proc. OFC, San Diego, CA, USA, Mar. 2015, pp.1-3.

[21] J. A. Altabas, et al., "Real-time 10Gbps Polarization Independent Quasicoherent Receiver for NG-PON2 Access Networks," in Proc. OFC, San Diego, CA, USA, Mar. 2018, pp.1-3.

[22] B. Cimoli, et al., "An ultra-wideband schottky diode based envelope detector for 2.5 Gbps signals," in Proc. EuMC, London, UK, 2016, pp. 277-280.

[23] Y. Luo, et al., "Time- and Wavelength-Division Multiplexed Passive Optical Network (TWDM-PON) for Next-Generation PON Stage 2 (NG-PON2)" J. Lightwave Technol., vol. 31, no. 4, pp. 587-593, Feb. 2013. 